Research Article

\title{
Research on the Negative Externalities Evaluation for the Development of Weathered Crust Elution-Deposited Rare Earth Ores
}

\author{
Xu Ligang $\mathbb{D}^{1,2}$ and Xu Meijuan ${ }^{2}$ \\ ${ }^{1}$ Beijing University of Science and Technology, Metal Mine Efficient Mining and Safety Ministry of Education Key Laboratory, \\ Beijing 100083, China \\ ${ }^{2}$ Jiangxi University of Technology Mining Development Research Center, Ganzhou, Jiangxi 341000, China
}

Correspondence should be addressed to Xu Ligang; just20040606@163.com

Received 19 July 2020; Revised 14 September 2020; Accepted 20 September 2020; Published 5 October 2020

Academic Editor: Hossein Moayedi

Copyright ( $\odot 2020 \mathrm{Xu}$ Ligang and Xu Meijuan. This is an open access article distributed under the Creative Commons Attribution License, which permits unrestricted use, distribution, and reproduction in any medium, provided the original work is properly cited.

\begin{abstract}
To standardize the specification of negative externality management of mining resources development and promote the process of marketization and diversification of ecological compensation, the article reviews the perspective and method of quantitative evaluation of negative externalities based on summarizing the mineralization principle, characteristics, and three-generation leaching process of weathered crust elution-deposited rare earth ore. Then, the principle of external loss in the process of mining and separation of weathered crust elution-deposited rare earth ore is analyzed and an external loss evaluation system is constructed. In this system, the market value method, shadow engineering method, and labor cost method are mainly used to measure and calculate the industrial "three-waste" pollution control expenses, ecological environment repair cost, and negative external derivative management cost of weathered crust elution-deposited rare earth ore development. Finally, based on the evaluation system, the data of the Longshe rare earth mining area in Jiading Town, Xinfeng County, was evaluated by the empirical study and it is obtained that the negative externality cost of the Longshe rare earth mining area in Xinfeng County is $102,900 \mathrm{RMB} / t$. National and local governments may refer to this model and data to strengthen the prevention and control of air, water, and soil pollution; scientifically control the ecological environment of weathered crust elution-deposited rare earth waste mines; and safeguard the livelihood and well-being of the residents of mining areas.
\end{abstract}

\section{Introduction}

Weathered crust elution-deposited rare earth ore refers to the black mica granite or volcanic rock in Yanshanian after the rock formation, wherein the feldspar after many years of $\mathrm{CO}_{2}, \mathrm{H}_{2} \mathrm{O}$, and organic acid weathering turned into clay containing halloysite, illite, kaolinite, montmorillonite, and other components. Weathered rare earth minerals dissociated out of hydrated ions or hydroxyl hydrated ions which were washed by rain and attached to clay $\left[\mathrm{Al}_{2} \mathrm{Si}_{2} \mathrm{O}_{5}\left(\mathrm{OH}_{4}\right)\right]_{m} \cdot n \mathrm{RE}^{3+}$ minerals. By the continuous weathering erosion and downward leaching development, rare earth ions eventually in the quaternary enriched and integrated the ore [1]. The main mineralization elements of the weathered crust elution-deposited rare earth ore include geotectonic location, construction, and deposition of rock magma, topography, and mineralization era. The colors are mainly gray, white, red, and yellow. According to the weathered crust species, it can be divided into plutonic rocks weathered crust, hypabyssal rocks weathered crust, and extrusive rocks weathered crust. According to geological storage type, it can be divided into full-duplex and barefooted type. The typical deposits are Longnan as the representative of heavy rare earth deposits, Xunwu as the representative of the light rare earth deposits, and Xinfeng as the representative of the middle yttrium and rich europium 
in rare earth deposits. Weathered crust elution-deposited rare earth ore is rich in medium-heavy rare earth elements, with a grade of about $0.03 \%$ to $0.15 \%$. It was first discovered in the mid-1960s, mainly distributed in Jiangxi, Fujian, Hunan, Guangxi, Guangdong, and other southern Provinces of the more humid and hotter climate of the hilly area. It has characteristics with small radioactivity, low cost, complete distribution, easy extraction, and so on. It exempts from crushing and mineral processing processes and directly through immersion to obtain rare earth oxides and in the military, metallurgy, petrochemical, ceramics, and other fields of application are quite extensive. China is the first country to mine and utilizes weathered crust elution-deposited rare earth ore. It began in the mid-1960s in the southern heavy rare earth resources base military trade union war. After more than 50 years of development, the leaching process has been continuously improved; as shown in Figures 1-3, it has from the $\mathrm{NaCl}$ leaching agent to the $\left(\mathrm{NH}_{4}\right)_{2} \mathrm{SO}_{4}$ leaching agent to the mixture of ammonium salt leaching agent, from the pool immersion to the heap leaching to the three generations of in situ leaching process of the progressive. Our research workers, without abroad ore mining and separation experience, adhere to the independent and finish the science and technology mission of the eighth, ninth, and tenth Five-Year [2]. Today, rare earth new materials are widely used to achieve high product added value in industries such as wind power, smartphones, new energy vehicles, and wearable batteries.

However, in the continuous development and production of weathered crust elution-deposited rare earth resources, no matter what kind of process, it will inevitably produce damage to the natural landscape, water resources, and human health, as shown in Table 1. This resulted in varying degrees of external loss, hindering the healthy development of ecological civilization in the new era.

The quantification and treatment of negative externalities of the development of weathered crust elutiondeposited rare earth ore is a complex process. For example, it is difficult to quantify the pollution of groundwater, and its influence on future generations is far-reaching. At present, there is no scientific and effective treatment method. $\mathrm{Hu}$ and $\mathrm{Wu}$ introduced the externality coefficient to evaluate the impact on the environment and economy [4]. Zhang used the threshold value of carbon emission as the governance standard of negative externalities [5]. Zhou thought to collect fuel tax and congestion fees to deal with the negative externalities in the field of transportation. Shubhayu calculated the negative externalities of mining residents' health based on statistical functions of related diseases [6]. Li and Zhang adopted the CVM method to measure the negative externality standard of coal development [7]. Bani-Mustafa et al. conducted a risk assessment of the negative external of nuclear power plants through the extension method of hypothesis deviation [8]. Experts and scholars at home and abroad use various methods to discuss the quantification of negative externalities from different evaluation angles. On the basis of previous studies, combined with the characteristics of weathered crust elution-deposited

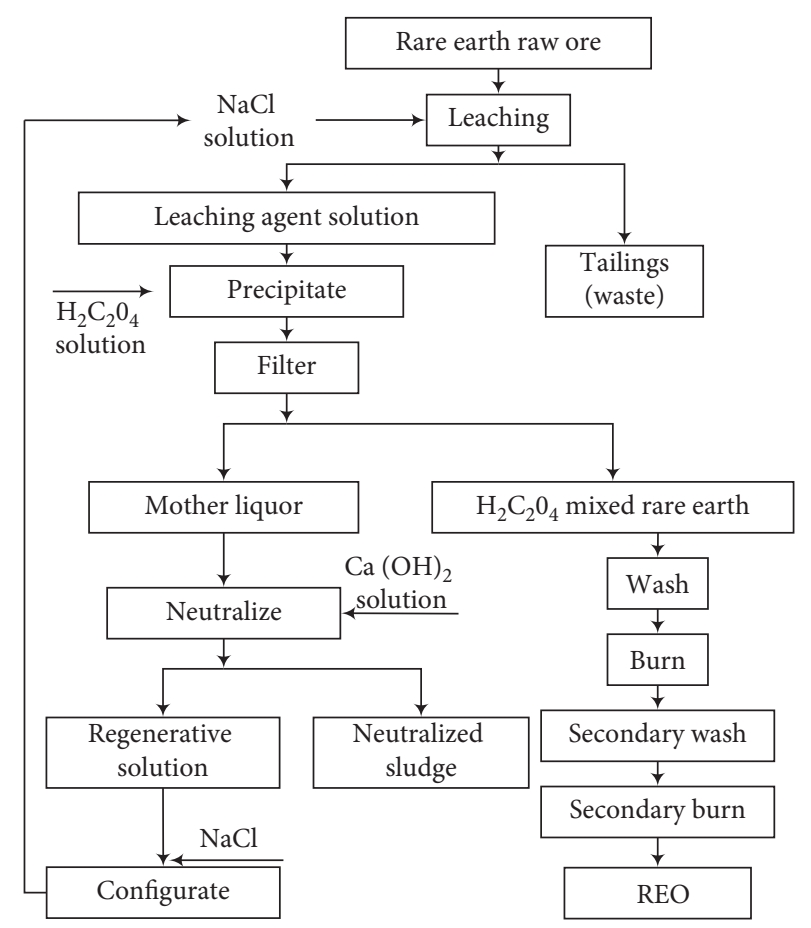

Figure 1: Weathered crust elution-deposited rare earth ore firstgeneration process.

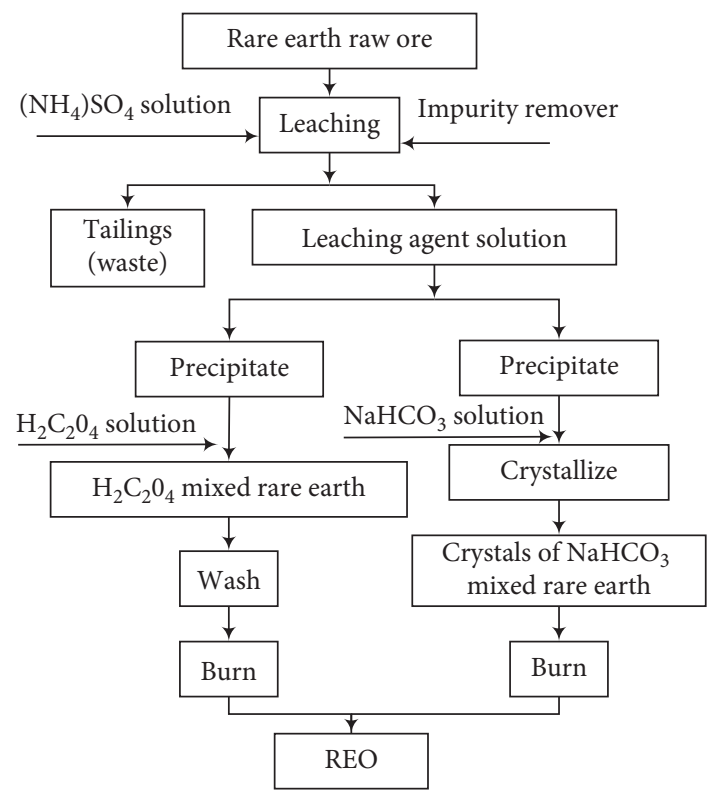

FIGURE 2: Weathered crust elution-deposited rare earth ore secondgeneration process.

rare earth ores development, a reasonable negative externality evaluation index system is constructed to effectively measure the development loss of weathered crust elution-deposited rare earth ores and to actively improve the quantitative evaluation of negative externality. It has provided reference for environmental governance and ecological compensation for residents in mining area, so as to realize the ecological balance of human resource development and natural survival. 


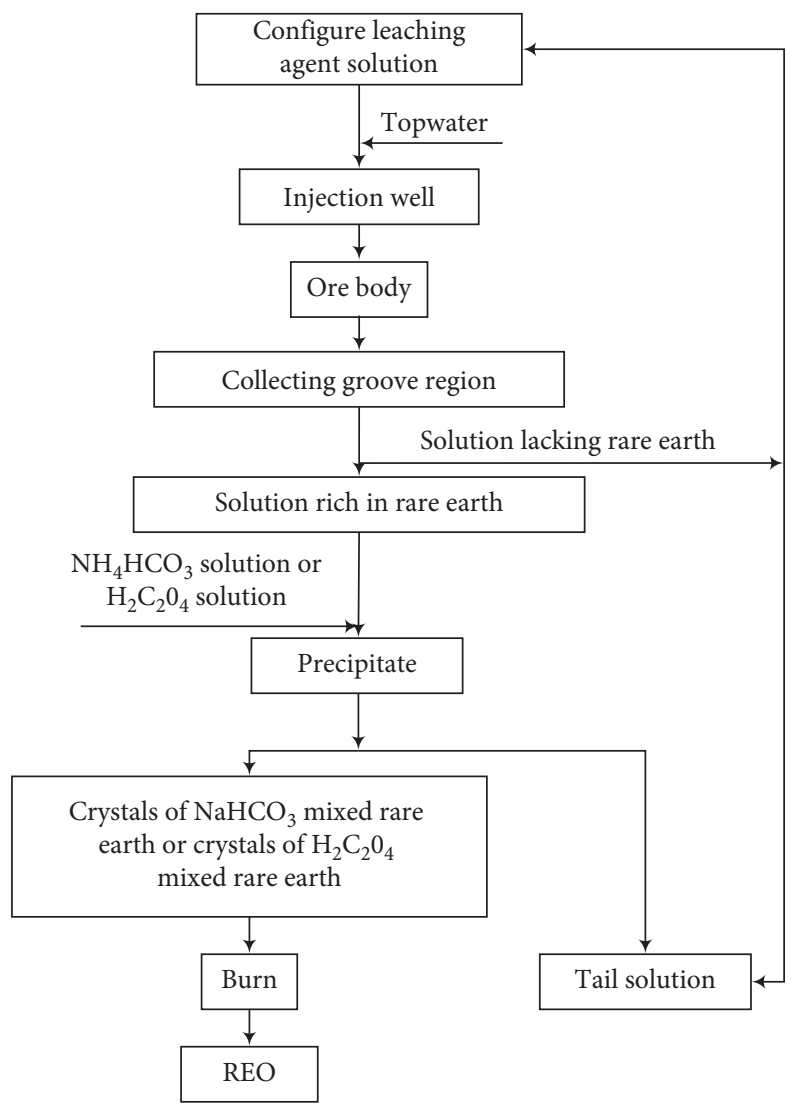

FIGURE 3: Weathered crust elution-deposited rare earth ore third-generation process.

TABLE 1: Weathered crust elution-deposited rare earth ore process characteristics and negative external effects [3].

\begin{tabular}{lccc}
\hline Process & First generation & Second generation & Third generation \\
\hline $\begin{array}{l}\text { Leaching } \\
\text { process } \\
\text { Leaching agent }\end{array}$ & Barrel leaching, pool leaching & Pool leaching, heap leaching & In situ leaching \\
Characteristics & Simple source and cheap leaching \\
agent & Low concentration leaching, improving \\
economic and social benefits & $\begin{array}{c}\text { Intact mountains and vegetation, } \\
\text { little infrastructure, and low cost, } \\
\text { improving efficiency }\end{array}$ \\
$\begin{array}{l}\text { Negative } \\
\text { externalities }\end{array}$ & $\begin{array}{c}\text { Inefficiency leaching, soil } \\
\text { salinization, destruction of mountain } \\
\text { landscape, and vegetation growth }\end{array}$ & $\begin{array}{c}\text { Tailing piles occupy a large amount of } \\
\text { land, destroy the ecological } \\
\text { environment, and cause soil erosion }\end{array}$ & $\begin{array}{c}\text { Contamination of groundwater; } \\
\text { improper injection is at risk }\end{array}$ \\
\hline
\end{tabular}

\section{Negative Externality Quantitative Evaluation Perspective}

2.1. Value of the Ecosystem's Services. Ecosystem services mainly refer to the services pay of the natural ecosystem for human survival and its economic activities [9]. At present, the evaluation of the service value of the ecosystem is mainly through three methods, which are the quality assessment of goods, the value assessment, and the analysis of energy value. The value measurement with the widest application can be divided into the actual market assessment, alternative market evaluation, and simulation market evaluation. The specific methods of actual market assessment are the market value method and expense method. The alternative market assessment is similar to the shadow price problem, which is used to obtain monetary value by the method of finding an equal amount of alternative goods. The simulation market assessment obtains economic value standard mainly by investigating the pay willingness of ecoservice users.

2.2. Ecological Loss Value. The value of ecological environment loss is a measure of the external loss brought to the ecological environment by economic subjects in economic activities; for example, the exploitation of mining resources brings not only external damage such as atmosphere, water, land, and forest but also the pollution caused by tailings reservoirs, waste storage, pollution of deep groundwater, and so on $[10,11]$. Even the surrounding residents' mental disorders are caused by the 
poor living environment such as noise. The calculation results of ecological loss value can be a reference for the low limit of negative externality quantitative evaluation. Simple mining development negative externality quantified Calculation Model is as follows:

$$
\mathrm{EC}=\sum_{i=1}^{n} E_{a} L_{i}+\sum_{i=1}^{n} E_{b} L_{i}+\sum_{i=1}^{n} E_{c} L_{i} .
$$

Related parameters are listed. In formula (1), the units are 10,000 yuan. EC is the amount of ecological compensation. $E_{a} L_{i}$ refers to the environmental pollution loss of the type of $i$ resource caused by mining development. $E_{b} L_{i}$ refers to the loss of ecological destruction value of the type $i$ resource caused by mining development. $E_{c} L_{i}$ refers to the spiritual loss of the type of $i$ resource caused by mining development. $\mathrm{N}$ is the number of types of mining resources.

Among them, the evaluation method of environmental pollution loss can be based on the market value method. The evaluation of ecological damage value loss is difficult to quantify, which can only be considered from the perspective of restoring the cost of the ecological environment before the destruction. And the mental loss is put on hold.

2.3. Cost of Ecological Restoration. Because of the inevitable exploitation of resources in human economic activities, which leads to the loss of part of the ecological function of the natural environment, it is necessary to invest a large number of people and property for restorative management. Following the principle of "who destroys, who governs," the cost of repairing governance after environmental damage is calculated as a reference for determining negative externalities quantitative evaluation. The waste of mining resources development, the equipment and materials need to repair environment and so on, can be calculated through the market value method. The cost of reclamation, planting, and maintenance can be calculated through the shadow engineering method and market value method. The residents around the mining area have a variety of physical diseases, and the treatment of various diseases requires certain medical expenses. These repair costs are important parameters for the quantitative evaluation of negative externality. However, when measuring accurately, it is difficult to define the identity of environmentalists and to estimate the input costs and individual opportunity cost losses of their environmental protection economic behavior [12].

2.4. Profit of the User. From the positive externality of environmental protection behavior, after repairing, the loss value of environmental damage was reduced and thus social welfare was improved. Users enjoy environmental protection products and services at the same time and do not pay. In order to expand the positive externality of environmental protection results and to encourage the active participation of environmental protection behavior, the beneficiary subject of environmental protection should be charged to positive externalities costs and in turn return to environmentalists. When quantifying the lost opportunity cost due to negative externality losses, it is considered from this perspective and calculated using the opportunity cost method.

However, the benefits of ecological environment protection are not necessarily characterized by strong material characteristics. Nonmateriality may make it difficult to achieve economic quantification. And sometimes the ecological beneficiary subject does not necessarily eventually become the subject of payment property rights, which brings many difficulties to the precise determination of negative external governance standards [13].

\section{Negative Externality-Quantified Evaluation Method}

3.1. Market Value Method. The market value method is the value of the services of an ecosystem that is measured by market prices. The cost of purchasing equipment required to deal with negative externalities, the cost of installation and maintenance, or market prices for finding alternatives due to negative externalities losses can be used as the basis for the quantification of negative externalities. This method is more dependent on market price and the more influence of the process and process of governance and the obvious difference between different regions and negative externalities indirect factors are not considered comprehensive, so there may be some deviation between the calculation results and the actual situation. Its expression is

$$
X=\sum_{i=1}^{n} \max X_{i}
$$

Parameter description: $X$ represents the market value of restoring the normal ecosystem and $X_{i}$ represents the market cost needed to deal with the negative externality of some waste.

3.2. Shadow Engineering Method. The Shadow engineering method is to find alternative products with a strong function when it is difficult to directly evaluate the value of ecological services. It can build shadow engineering, simplify the evaluation procedure, and measure its environmental investment and maintenance cost, which is mainly used for vegetation or natural landscape destruction and other negative externalities quantitative evaluation reference. Its expression is

$$
C=F\left(x_{1}, x_{2}, x_{3}, \ldots, x_{n}\right) .
$$

Parameter description: $C$ represents the functional value of the ecosystem and $X_{n}$ represents the investment cost of each project in the alternative project. The characteristic of this method is to replace the unmeasurable externality loss value with the other industries' economic value which can be calculated simply, which improves the operability of quantitative evaluation. Of course, when looking for alternative shadow projects, there may be a variety of industries to choose from, so the calculation standard cannot be unified. Only reasonable shadow projects can be selected 
according to the actual needs of external governance, or the average value of various shadow projects can be calculated as the quantitative standard for the evaluation of negative externalities.

3.3. Labor Cost Method. The labor cost method mainly considers the loss of human health caused by negative externality, including the loss of labor value and the cost of recovery of health. Based on the level of local economic development, the average wage of workers, the incidence of some sort of disease, and the cost of health care, the number of people affected is the parameters of negative externality evaluation. However, this method cannot obtain specific pathogenic factors; the scope and extent of its impact cannot be accurately determined.

Its expression is

$$
\mathrm{LC}=W+F
$$

Parameter description: LC represents labor cost, $W$ represents labor value loss, and $F$ represents health recovery cost.

3.4. Opportunity Cost Method. The opportunity cost method mainly refers to the opportunity to lose the development of other industries due to the development of one industry. It is the opportunity cost which is the greatest economic benefit that the abandoned industry may gain. This method applies to the lack of market data and a wide range of other industries. Its expression is

$$
\mathrm{OC}=\max \left(P_{1}, P_{2}, P_{3}, \ldots, P_{n}\right) .
$$

Parameter description: OC represents opportunity cost and $P_{n}$ represents the income of the $n$-th kind of industry that was forced to give up.

3.5. Contingent Valuation Method. Contingent valuation method (CVM) was introduced by Davis in 1963, which examine directly the respondents' conduct in the hypothetical market to obtain the consumer's willingness to pay (WTP) or the willingness to accept (WTA). And it is a way to derive the economic value of environmental efficiency improvements or environmental quality loss and then to measure the value of goods or services $[14,15]$.

The economic interpretation of CVM: through a random survey of questionnaires, consumers' preferences are revealed, and equal utility points of consumers in different environmental states are deduced. The expression of the indirect utility function is $V_{0}\left(p, q_{0}, y, s, \varepsilon\right)=V_{1}\left(p, q_{1}, y-w, s, \varepsilon\right)$ and the economic value of environmental goods or services is obtained through the quantitative determination of the distribution law of willingness to pay $w$. Parameter description: it is assumed that the utility function of consumers is influenced by market goods $p$, nonmarket goods $q$ (which will be valued), and personal preference $s$. The indirect utility function is not only affected by market goods $p$, personal income $y$, personal preference $s$, and nonmarket goods $q$ but also affected by some random components such as personal preference error and measurement error. If this random component is represented by $\varepsilon$, the indirect utility function can be represented by $V(p, q, y, s, \varepsilon)$. Respondents are usually faced with the possibility of a change in the state of the environment (from-to $q_{1}$ ), assuming that the change in the state is an improvement, that is, $V_{0}\left(p, q_{0}, y, s, \varepsilon\right) \leq V_{1}\left(p, q_{1}, y-w, s, \varepsilon\right)$; the improvement of this state requires a certain amount of money from consumers.

3.6. Comparison of Evaluation Methods. On the basis of analyzing the theory of various evaluation methods, the amount of data required, the difficulty of obtaining data, the complexity of calculation, and applicability are scientifically compared when a negative externality quantitative evaluation system is used for the development of weathered crust elution-deposited rare earth ore. It is shown in Table 2 for the selection of the evaluation system.

\section{Negative Externality Performance in the Development of Weathered Crust Elution-Deposited Rare Earth Ore}

The negative externality of the development of weathered crust elution-deposited rare earth ore mainly means that, in the process of rare earth resource development, the terrain and mountain view are destroyed which resulted in soil erosion and landslides, the polluting surrounding of water ecological environment, and soil ecological environment which caused certain damage to animals, plants, and human health.

4.1. "Three-Waste" Pollution in the Industry of the Development of Weathered Crust Elution-Deposited Rare Earth Ore. The waste was produced in the process of the precipitation, extraction, and separation, which refers to the toxic and harmful gases, polluting wastewater, and waste residue emitted in the production process of weathered crust elution-deposited rare earth ore, among which the destruction of water resources is the most serious. Each production of $1 \mathrm{t}$ weathered crust elution-deposited rare earth concentrates (REO 92\%) consumes 1500 to 2400 t rare earth raw minerals and the amount of "three-waste" pollution discharged is shown in Table 3.

At present, the separation method of weathered crust elution-deposited rare earth ore mainly by using $\mathrm{NH}_{4} \mathrm{HCO}_{3}$ or $\mathrm{H}_{2} \mathrm{C}_{2} \mathrm{O}_{4}$ precipitation will inevitably produce many wastewater containing ammonia nitrogen, including $\left(\mathrm{NH}_{4}\right)_{2} \mathrm{SO}_{4}$ and $\mathrm{NH}_{4} \mathrm{Cl}$ two types, of which the treatment of $\left(\mathrm{NH}_{4}\right)_{2} \mathrm{SO}_{4}$ wastewater is more difficult. So far, there is no reasonable treatment process [17]. The presence of $\mathrm{NH}_{4}^{+}$may cause changes in the chemical morphology of heavy metals such as $\mathrm{Cu}, \mathrm{Cd}$, and $\mathrm{Zn}$, which will affect the ability to migrate and transform. Toxic and harmful ammonia nitrogen and nitrate nitrogen wastewater recovery and treatment costs are high. Most rare earth mining enterprises discharged without treatment or incomplete treatment. Groundwater is polluted by the long-term residue in the land and constantly penetrating the low-lying groundwater layer. 
TABLE 2: Comparison of quantitative evaluation methods of the negative externality.

\begin{tabular}{|c|c|c|c|c|}
\hline Evaluation methods & Theoretical basis & Data volume & Complexity & Applicability \\
\hline Market value method & Theory of supply and demand & Medium & Simple & Strong \\
\hline Shadow engineering method & Ecological service theory & Small & Simple & Strong \\
\hline Human cost method & Wage theory & Medium & Complex & Weak \\
\hline Opportunity cost method & Utility value & Small & Simple & Strong \\
\hline Contingent valuation method & Consumer preference theory & Big & General & Medium \\
\hline
\end{tabular}

TABLE 3: The amount of pollution caused by weathered crust elution-deposited rare earth ore from the production units [16].

\begin{tabular}{lcc}
\hline Pollutants produced & Unit & Amount of pollution \\
\hline Amount of industrial wastewater & $\mathrm{m}^{3} / \mathrm{t}$ & 750.00 \\
Chemical oxygen demand & $\mathrm{g} / \mathrm{t}$ & $98,250.00$ \\
Ammonia nitrogen & $\mathrm{g} / \mathrm{t}$ & 913.00 \\
Industrial solid waste & $\mathrm{t} / \mathrm{t}$ & 0.913 \\
\hline
\end{tabular}

The consequences are not conceivable. The $\mathrm{O}_{2}$ content of weathered crust elution-deposited rare earth concentrate is less than $0.002 \%, \mathrm{U}_{3} \mathrm{O}_{8}$ content is less than $0.032 \%$, and the total specific activity of radiation is $2 \times 10^{4} \mathrm{~Bq} / \mathrm{kg}$ [18]. Most enterprises have not yet established radioactive acid slag tailings, which resulted in radioactive contamination.

The three-generation leaching process of weathered crust elution-deposited rare earth ore has one thing in common, which is that by burning wood or coal, the newly leached oxalic or carbonic rare earth burns into rare earth mixtures, which emit many toxic and harmful exhaust gas such as smoke, dust, and $\mathrm{SO}_{2}$ [19]. The separation and electrolysis process of weathered crust elution-deposited rare earth ore requires the use of a concentrated $\mathrm{HCl}$ with an $\mathrm{HCl}$ gas content of $6 \mathrm{~kg} / \mathrm{h}$ in the decomposition tank, which exceeds the national emission standard by 2.72 times [20]. At present, the vast majority of rare earth mineral processing plants for toxic and harmful gases treatment ratio has reached more than $85 \%$, but there are still very few private small enterprises discharging the waste gas untreated or not up to standard, which will cause mining workers and surrounding residents of various diseases to significantly increase.

Weathered crust elution-deposited rare earth ore in the process of mining and separation will produce a large amount of solid waste such as tailings and waste residue [21]. According to incomplete statistics, the Gannan rare earth mine will produce an average of at least 13 million $\mathrm{m}^{3}$ of solid waste per year [22]. The vast majority of mining enterprises directly to leaching residue as a general sludge treatment, not according to the standard setup tailings reservoir. In the rainstorm weather, it will be washed with rain, covering the downstream riverbed and farmland.

4.2. Weathered Crust Elution-Deposited Rare Earth Ore Development Leads to Ecological Damage. The pool immersion process will cut or burn the above layer of the vegetation, that is, stripping the topsoil layer. After mining the ionized rare earth ore, a large area of vegetation and land is destroyed. Relevant data show that the early use of the pool immersion process production $1 \mathrm{t}$ weathered crust elution- deposited rare earth concentrate needs to peel off $300 \mathrm{~m}^{2}$ of the topsoil layer, damage 160 to $200 \mathrm{~m}^{2}$ of the surface vegetation, resulting in soil erosion of about $1200 \mathrm{~m}^{3}$ per year and soil desertification area of about $1 \mathrm{mu}$ [23]. Vegetation destruction can also lead to a sharp decline in the number of local wildlife, affecting biodiversity and the ecosystem balance around the mine.

The destruction of the topsoil layer by the pool immersion and heap immersion process will lead to the loss of soil organic matter, nitrogen, phosphorus, and other nutrients in the location of rare earth mining destroying the microbial balance in the land ecosystem. And the physical and chemical properties of soil $\mathrm{pH}$, porosity, particle density, and so on have also been destroyed. Its texture has become loose and poor water holding capacity.

4.3. Negative External Derivative Effects of Weathered Crust Elution-Deposited Rare Earth Development. The ammonia nitrogen wastewater mentioned above destroyed the freshwater resources and water quality structure of weathered crust elution-deposited rare earth ore seriously affects the irrigation water for agricultural production around the mine and also poses a threat to drinking water for the sake of water safety, all of which can only be purchased from other places [24]. The separation process of weathered crust elution-deposited rare earth ore discharges toxic and harmful gases, causes long-term exposure to the air, and easy to cause respiratory tract, lung, and skin diseases of the surrounding residents. Besides, the pollution of rare earth elements in soil, water, and crops around the mining area is very serious. Those tailings contain a lot of heavy metal elements such as $\mathrm{As}, \mathrm{Cd}$, and $\mathrm{Pb}$. And through the food chain, the health of mining workers and surrounding residents were threatened in the bones, blood, and hair accumulation, which resulted in decreased immunity, induced osteoporosis, and brain toxic effects, especially stunted children, increasing the burden of medical consumption of the surrounding residents of the mining area [25]. In the process of protecting the ecological balance of weathered crust elutiondeposited rare earth mining areas, some development opportunities of other industries have also been lost, resulting in certain losses.

\section{Weathered Crust Elution-Deposited Rare Earth Ore Development Negative Externality Quantitative Evaluation System Construction}

According to the previous analysis, weathered crust elutiondeposited rare earth ore development negative externality is of the following three main aspects, namely, industrial "three- 
waste" pollution, ecosystem destruction, and negative external derivative impact. Therefore, in the negative externality quantitative evaluation, the characteristics of a variety of evaluation angles were combined and then the negative externality of the marketization and diversification trend was considered. It should include "three-waste" pollution control costs, ecosystem restoration costs, and derivative costs, as shown in Table 4. In the selection of negative externalities quantitative evaluation method, the main reference is to its theoretical basis, the requirements of data volume, the complexity of calculation, and the degree of applicability. Based on a comprehensive evaluation index and evaluation method, weathered crust elution-deposited rare earth ore development external quantitative evaluation system was built.

\subsection{Industrial "Three-Waste" Pollution Control Costs}

5.1.1. Wastewater Treatment Costs. With reference to the level of wastewater treatment of weathered crust elutiondeposition rare earth resources, according to the market value method, it is estimated that

$$
X_{1}=\sum_{i=1}^{m}\left(O_{i} \times C_{i}\right) \times T_{1} .
$$

Related parameters: in the previous formula, $X_{1}$ is the cost of wastewater treatment for weathered crust elutiondeposited rare earth ore; $\mathrm{O}_{i}$ is the unit time discharge of the $\mathrm{i}_{\mathrm{th}}$ kind of wastewater; $C_{i}$ is the treatment cost of the $i$-th kind of wastewater; $T_{1}$ is the mine operation time; $m$ is the types of wastewater discharged from mines.

5.1.2. Waste Gas Treatment Costs. Referring to the "Rare Earth Industrial Pollutant Emissions Standard" and the level of waste gas treatment of weathered crust elution-deposited rare earth resources, the estimate is made according to the market value method:

$$
X_{2}=\sum_{j=1}^{n}\left(O_{j} \times C_{j}\right) \times T_{2}
$$

Related parameters: in the previous formula, $X_{2}$ is the cost of exhaust gas treatment for weathered crust elutiondeposited rare earth ore; $\mathrm{O}_{j}$ is the unit time discharge of the $j$ th kind of exhaust gas; $C_{j}$ is the treatment cost of the $j$ th kind of exhaust gas; $T_{2}$ is the mine operation time; $n$ is the types of exhaust gas discharged from mines.

5.1.3. Waste Residue Treatment Costs. The cost of waste residue treatment in weathered crust elution-deposited rare earth mine can be divided into radioactive waste residue treatment cost $a$ and nonradioactive waste residue treatment $\operatorname{cost} b$. With reference to waste residue storage establishment and the deposit price, according to the market value method for estimation,

$$
X_{3}=\left(O_{a} \times C_{a}+O_{b} \times C_{b}\right) \times T_{3} .
$$

Related parameters description: in the previous formula, $X_{3}$ is the cost of waste residue treatment for weathered crust elution-deposited rare earth ore; $O_{a}$ is the unit time discharge of radioactive waste residue; $O_{b}$ is the unit time discharge of nonradioactive waste residue; $C_{a}$ is the treatment cost of radioactive waste residue; $C_{b}$ is the treatment cost of nonradioactive waste residue; and $T_{3}$ is the mine operation time.

\subsection{Cost of Ecological Restoration}

5.2.1. Vegetation Restoration Costs. Vegetation restoration mainly consists of several steps, such as planting and fertilization and routine maintenance. The planting cost of vegetation includes seedlings, water, and labor cost. Fertilization cost includes fertilizer and labor costs. Maintenance costs include labor and machinery costs, which are estimated according to the shadow engineering method:

$$
Y_{1}=\sum_{k=1}^{m}\left[S_{k} \times\left(C_{k 1}+C_{k 2}+C_{k 3}\right)\right] \text {. }
$$

Description of relevant parameters: in the previous formula, $Y_{1}$ is the cost of vegetation restoration for weathered crust elution-deposited rare earth ore; $S_{k}$ is the area of $k_{\text {th }}$ kind of vegetation; $C_{k 1}$ is the cost of $k_{\text {th }}$ kind of vegetation planting; $C_{k 2}$ is the fertilization cost of $k_{\text {th }}$ kind of vegetation; $C_{k 3}$ is the daily maintenance cost of $k_{\mathrm{th}}$ kind of vegetation; and $m$ is the number of vegetation types.

5.2.2. Land Restoration Costs. The main quantitative consideration of land restoration costs is the cost of filling or leveling the damaged land and the cost of restoring the soil ecosystem. Estimated according to the shadow engineering method,

$$
Y_{2}=S \times\left(C+\sum_{l=1}^{n} P_{l} \times Q_{l}\right) \times \delta .
$$

Related parameters: in the previous formula, $Y_{2}$ is the cost of land restoration for weathered crust elution-deposited rare earth ore; $S$ is the area for damaged land; $C$ is the cost of filling or leveling for land; $P_{l}$ is the repair agent price for the $l$-th kind of soil; $Q_{l}$ is the amount of the $l$-th kind of soil repair agent; $\delta$ is the correction coefficient, affected by the economic development of weathered crust elution-deposited rare earth resources and land restoration type, and so forth. The value of the correction coefficient is from 0.8 to 1.2 .

\subsection{Negative External Derivative Governance Costs}

5.3.1. Residents' Health Recovery Costs. The cost of loss of residents' health mainly includes the loss of labor value and medical expenses, which are estimated according to the labor cost method:

$$
Z_{1}=\left[P \sum_{r=1}^{m} T_{r}\left(L_{r}-L_{r^{\prime}}\right)+\sum_{r=1}^{m} Y_{r}\left(L_{r}-L_{r^{\prime}}\right)\right] \times M .
$$

Related parameters: in the previous formula, $Z_{1}$ is the cost of health loss for residents of weathered crust elution- 
TABLE 4: The overhead expenses of the negative externality of exploiting weathered crust elution-deposited rare earth ore.

\begin{tabular}{lcc}
\hline Negative external treatment costs & Evaluation indicators & Evaluation methods \\
\hline Industrial "three-waste" & Wastewater treatment & \\
Pollution treatment costs & Exhaust gas treatment & Market value method \\
Ecosystems & Waste residue treatment & \\
Recovery costs & Vegetation restoration & Shadow engineering method \\
& Land restoration & Market value method \\
Derivative costs & Health recovery & Labor cost method \\
& Cost of water & Market value method \\
& Other losses & Opportunity cost method \\
\hline
\end{tabular}

deposited rare earth ore; $P$ is the price of human capital; $T_{r}$ is the lost time for the $r$-th kind of disease; $Y_{r}$ is the cost of medical care for the $r$-th kind of disease; $M$ is the number of residents; $L_{r}$ is the incidence rate for the $r$-th kind of disease in the contaminated areas; and $L_{r^{\prime}}$ is the incidence rate for the $r$-th kind of disease in the uncontaminated areas.

5.3.2. Production and Living Water Costs. With reference to the water consumption and unit price of production and life and with the help of the market value method for estimating,

$$
Z_{2}=C_{1} \times Q_{1}+C_{2} \times Q_{2} .
$$

Related parameters description: in the previous formula, $Z_{2}$ is the production and living water costs for the weathered crust elution-deposited rare earth ore; $C_{1}$ is the price of production water; $Q_{1}$ is the quantity of production water; and $Q_{2}$ is the quantity of living water.

5.3.3. Opportunity Costs. With the marginal opportunity cost method, the opportunity cost of other industries affected by negative externalities is estimated:

$$
Z_{3}=\max \left\{P_{1}, P_{2}, P_{3}, \ldots, P_{i}\right\} .
$$

Related parameters: in the previous formula, $Z_{3}$ is the marginal cost of negative externality management for weathered crust elution-deposited rare earth ore and $P_{i}$ is the marginal revenue for the development of the $i$-th kind of industry.

\section{Weathered Crust Elution-Deposited Rare Earth Ore Development Negative Externality Quantitative Evaluation Empirical Research}

In the producing area of weathered crust elution-deposited rare earth ore, Ganzhou City, Jiangxi Province, the existing waste rare earth has 408 . A total area is about $93.88 \mathrm{~km}^{2}$, which is mainly distributed in Xinfeng, Longnan, XunWu, and Anyuan counties. The top list is Xinfeng, which has 64 waste rare earth ores and the annual production of REO once reached a peak of $4000 \mathrm{t}$. Its rare earth ore is mainly distributed in Xintian, Anxi, and Hushan. Xinfeng County Longshe Rare Earth Mine Area is located in Jiading Town, which is $8 \mathrm{~km}$ to the east of the county town and the mining area is about $200 \mathrm{hm}^{2}$. Its rare earth minerals formation is by granite weathering and the main chemical composition is
$\mathrm{KAlSi}_{3} \mathrm{O}_{8}, \quad \mathrm{NaR}_{3} \mathrm{Al}_{6}\left[\mathrm{Si}_{6} \mathrm{O}_{18}\right]\left[\mathrm{BO}_{3}\right]_{3}(\mathrm{OH}, \mathrm{F})_{4}, \quad \mathrm{Al}_{2} \mathrm{Si}_{2} \mathrm{O}_{5}$ $(\mathrm{OH})_{4}, \mathrm{SiO}_{2}, \mathrm{KAl}_{2}\left[\mathrm{AlSi}_{3} \mathrm{O}_{10}\right](\mathrm{OH})_{2}$, etc., which is rich in bastnaesite and belongs to the typical Eu rich and medium yttrium rare earth ore [26]. Since the 1980s, Longshe rare earth ore has more than 500 spots in its heyday with an annual REO production of about $2000 \mathrm{t}$. Only in 2000, it gradually transforms from the barrel leaching process and pool leaching process to in situ leaching process. Nearly 50 years of rare earth mining, it has resulted in the tail sand covering an area of about $13 \mathrm{~km}^{2}$ and the rising of Longshe river bed by about $2 \mathrm{~m}$, eradication and destruction of vegetation, deposition of many mines, the erosion of soil, the destruction of fertile farmland, and the blocking of rivers. All these are showing the declining scene with the naked grass and many ravines. Various heavy metal ions also pollute the water resources of the mining area, which has a great impact on the lives of the surrounding villagers. Due to the low degree of attention, unclear responsibility, lack of funds, and other reasons, some mines even exist in the unknown location and its area is inaccurate. The negative external governance process is slow. The data in this article are mainly derived from the Yearbook of the Chinese Rare Earth Society (2018), the Standard Management Measures for The Collection of Sewage Charges (2017), Investigation and Research on Longshe Rare Earth Mining Area in Xinfeng County, Survey Report on the Environmental of Abandoned Mines in Xinfeng County (2018), the Quota for Living Water in Jiangxi Province (2017), the 2015-2018 National Economic and Social Development Statistics Bulletin of Xinfeng County, etc.

\section{1. "Three-Waste" Pollution Control Costs in the Longshe Rare Earth Mining Area of Xinfeng County}

6.1.1. Wastewater Treatment Costs. The wastewater discharged from the Longshe rare earth mining area in Xinfeng County is mainly $\mathrm{NH}_{4} \mathrm{Cl}$ wastewater and $\left(\mathrm{NH}_{4}\right)_{2} \mathrm{SO}_{4}$ wastewater, of which the $\mathrm{NH}_{4}^{+}-\mathrm{N}$ concentration is above $1000 \mathrm{mg} / \mathrm{L}$. It can be seen from Table 3 that the emissions per $1 \mathrm{t}$ of rare earth concentrate are $750 \mathrm{t}$. The cost of wastewater treatment is calculated by alkaline steaming ammonia treatment ammonium salt. The treatment of ammonia nitrogen wastewater and industrial wastewater includes equipment procurement and depreciation, chemical agents, hydropower, and manpower [27]. The price of the county of Xinfeng is 0.46 yuan/t, 0.83 yuan/t, 0.51 yuan/t, and 0.44 yuan/ 
t. After the conversion of the unit price is 0.0015 ten thousand yuan/t, the annual costs of wastewater treatment are

$$
X_{1}=750 \times 0.0015 \times 2000=2250(\text { ten thousand yuan), }
$$

6.1.2. Exhaust Gas Treatment Costs. The emissions of separation and electrolysis process of thick $\mathrm{HCl}$ gas from the weathered elution-deposited rare earth ore are approximately $6.0 \mathrm{~kg} / \mathrm{h}$, which can be absorbed by the shock of $\mathrm{Na}_{2} \mathrm{CO}_{3}$ and $\mathrm{NaOH}$ solution. And then, it becomes $\mathrm{NaCl}$ crystal by distilling. The initial installation cost of exhaust gas treatment equipment in the Longshe rare earth ore is about 15 ten thousand yuan. $\mathrm{HCl}$ gas treatment price of the Chemical Industry in Ganzhou is 0.0018 ten thousand yuan/ $\mathrm{kg}$. The designed service life is 25 years. If the use time is $12 \mathrm{~h}$ per day, the total annual use time is $4380 \mathrm{~h}$. The annual costs of exhaust gas treatment are

$$
\begin{aligned}
X_{2} & =6.0 \times 0.0018 \times 4380+15 \div 25 \\
& \approx 47.9 \text { (ten thousand yuan) } .
\end{aligned}
$$

6.1.3. Waste Residue Treatment Costs. Based on the radioactive characteristics of solid waste such as tailings and waste discharges during the mining and separation of weathered crust rare earth ore, it can be divided into general waste residue and radioactive waste residue (total $\alpha$ specific activity is about $1.23 \times 10^{5} \mathrm{~Bq} / \mathrm{kg}$, and total $\beta$ specific activity is about $9.26 \times 10^{4} \mathrm{~Bq} / \mathrm{kg}$ ) and the corresponding tailings reservoir needs to be established for treatment. According to the Standard Management Measures for The Collection of Sewage Charges (2017), the treatment cost of the general waste residue storage is 0.0015 ten thousand yuan/t, while the radioactive residue storage is relatively higher and requires "three precautions" (rainproof, antiseepage, and windbreak) treatment and so forth at a cost of about 0.55 thousand yuan/t. According to the annual production of REO in the Longshe rare earth mining area, the emissions of general waste and radioactive waste residue are $20000 \mathrm{t}$ and $300 \mathrm{t}$, respectively, and the annual costs of waste residue treatment are

$$
\begin{aligned}
X_{3} & =0.0015 \times 20000+0.55 \times 300 \\
& =195 \text { (ten thousand yuan) } .
\end{aligned}
$$

\subsection{Cost of Ecological Environment Restoration in Longshe Rare Earth Mining Area in Xinfeng County}

6.2.1. Vegetation Restoration Costs. According to the destruction of vegetation from Longshe rare earth mining area, the average annual vegetation destruction area is $0.65 \mathrm{~km}^{2}$, while the vegetation restoration method of Longshe rare earth mining area is mainly planted with umbilical orange. According to the 2018 data of Ganzhou Municipal Fruit Industry Bureau, the planting unit price of umbilical orange seedlings is 12 yuan/plant, planting density is about 160,000 plants $/ \mathrm{km}^{2}$. The umbilical orange seedling saline planting time is $25 \mathrm{a}$. The planting cost of the orange seedlings in the Longshe rare earth mining area can be calculated as $12 \times 16 \div 25=7.68$ ten thousand yuan $/ \mathrm{km}^{2}$. The total fertilization cost of umbilical orange planting is 2.4 ten thousand yuan $/ \mathrm{km}^{2}$ and the daily maintenance cost is 1.1 ten thousand yuan $/ \mathrm{km}^{2}$. The vegetation restoration cost is estimated using the shadow engineering method, and the annual costs of vegetation restoration are

$$
Y_{1}=0.65 \times(7.68+2.4+1.1) \approx 7.3(\text { ten thousand yuan }) \text {. }
$$

6.2.2. Land Restoration Costs. According to the "Xinfeng County abandoned mine environmental investigation report," Longshe rare earth ore area covers an area of about $13 \mathrm{~km}^{2}$. In recent years, to actively manage abandoned rare earth mines, Xinfeng County plans to build a sand-blocking water storage project in the foothills of the Longshe ore area, the mountainside construction antislope ladder belt, the remaining slope planting slope grass belt, and so forth. Its land reclamation cost is about 20 yuan $/ \mathrm{m}^{2}$. According to the economic development level of Xinfeng County, the cost of soil remediation is 2.8 ten thousand yuan/mu for land recovery completion time meter $25 \mathrm{a}$. The annual costs of land restoration are

$$
\begin{aligned}
Y_{2} & =13 \times 10^{6} \times(0.002+2.8 \times 0.0015) \div 25 \\
& =3224 \text { (ten thousand yuan) } .
\end{aligned}
$$

\subsection{Negative External Derivatives Management Costs in the Longshe Rare Earth Ore Area of Xinfeng County}

6.3.1. Costs of Health Loss to Residents. The affected population of the Longshe rare earth ore area in Xinfeng County is about 0.6 ten thousand and the monthly wage of local migrant workers is about 2500 yuan. The mining and separation process of rare earth mine will lead to a significant increase in the incidence of respiratory diseases and cancer. Limited to the constraints of data collection, this paper mainly discusses the health loss caused by respiratory diseases. There is no weathered crust elution-deposited rare earth mining in Shicheng County, which can be as a reference object. According to the labor health survey, Xinfeng County and Shicheng County, two counties of respiratory disease, incidence rate is $18.2 \%$ and $11.9 \%$ respectively. The medical cost of the disease is 120 yuan/person.d. The annual costs of health loss for its residents are

$$
\begin{aligned}
Z_{1}= & (2500+120 \times 30) \times(18.2 \% \text { o }-11.9 \% \text { o }) \\
& \times 12 \times 0.6 \approx 276.7(\text { ten thousand yuan })
\end{aligned}
$$

6.3.2. Costs of Water Loss in Production and Life. Affected by weathered crust elution-deposited rare earth ore, the residential water used by residents of Longshe mining areas needs to be purchased from other places. According to the Quota for Living Water in Jiangxi Province (2017), the 
amount of water used by residents is $100 \mathrm{~L} /$ (people.d). The price is calculated at 1.15 yuan/t and the density of water is $1 \mathrm{~g} / \mathrm{cm}^{3}$, which is $0.001 \mathrm{t} / \mathrm{L}$. The annual costs of water loss for production and living are

$$
\begin{aligned}
Z_{2} & =1.15 \times 100 \times 0.001 \times 12 \times 30 \times 0.6 \\
& \approx 24.8(\text { ten thousand yuan }) .
\end{aligned}
$$

6.3.3. Costs of Opportunity. Residents of the Longshe rare earth mining area of Xinfeng County have lost opportunities to develop other industries such as cultivation, work, and tourism due to weathered crust elution-deposited rare earth mining. According to the actual situation of agricultural production in Jiading Town, the cultivation of navel orange has formed economies of scale in the local area; therefore, the opportunity cost loss of rare earth mining is mainly the production profit of the navel orange industry. After ripening, the navel orange fruit tree has an annual profit of 70 yuan/ plant with a planting density of about 160,000 plants $/ \mathrm{km}^{2}$ and the annual costs of opportunity loss of weathered crust elution-deposited rare earth ore are

$$
Z_{3}=13 \times 16 \times 70=14560 \text { (ten thousand yuan) } .
$$

6.4. Comprehensive Evaluation. Referring to the negative externality quantitative evaluation system of the development of weathered crust elution-deposited rare earth ore and the previous empirical analysis data, the overall cost of the negative externality of Longshe rare earth mine development should be

$$
\begin{aligned}
\mathrm{EC} & =X_{1}+X_{2}+X_{3}+Y_{1}+Y_{2}+Z_{1}+Z_{2}+Z_{3} \\
& =20585.7 \text { (ten thousand yuan). }
\end{aligned}
$$

Xinfeng County Longshe rare earth mining area REO annual output is $2000 \mathrm{t}$, which converted negative externalities quantitative cost of 10.29 ten thousand yuan/t. Compared with the existing rare earth mine negative externality compensation standard of 35 ten thousand yuan/t, the deviation is large. It is indicated that the national and local governments' negative externality management in the weathered crust elution-deposited rare earth ore should also overcome difficulties and further increase the investment of funds. Compared with Ma Guoxia's 20.3 ten thousand yuan/ t [28] and Laidan's 3.83 ten thousand yuan/t [29], the coverage of the quantitative evaluation indicators varies by some degree and the path to data acquisition varies. Of course, this study is subject to the collected data. Biodiversity loss and noise pollution have not been considered. In future studies, it should be considered more objective and comprehensive.

The empirical study of negative externalities quantitative evaluation of the development of Longshe rare earth mine in Xinfeng County has certain reference value and significance for the inspection of the negative externality quantitative evaluation system and the management of waste rare earth mines. On this basis, local governments can explore the principles of adjusting measures to local conditions for cultivation, planting, water, and factory. Then financing channels gradually are established by the principle of "who invests, who benefits," which encourage the government, enterprises, and individuals to invest in a variety of ways, promote the ecological compensation market operation mode, develop governance mode, and speed up the pace and process of management of weathered crust elution-deposited rare earth waste ores [30, 31].

\section{Conclusion}

The evaluation system of negative externalities of rare earth in the weathered crust has been constructed, and the results are mainly obtained from three aspects:

(i) The negative externalities caused by different processes are analyzed and compared by changing the three-generation leaching processes chart of weathered crust elution-deposited rare earth.

(ii) The applicability of various evaluation methods in various fields of negative externalities of the rare earth industry has been comprehensively integrated, and the theoretical research direction of negative externalities evaluation has been broadened by the cross-application of multiple disciplines.

(iii) Taking Longshe rare earth mine as a case study, according to its development characteristics, the negative external governance is divided into three parts: industrial "three-waste" pollution, ecological environment remediation, and derivative governance. The governance standards calculated can provide reference and basis for national and local governments.

Due to the limitations of the analysis of negative externalities of weathered crust elution-deposited rare earth, such as the pollution of groundwater, the standard of effective treatment is still worth discussing, and the negative external evaluation index system is not reasonable. In terms of data acquisition and applicability, the author's subjective choice is also limited, and the calculation method is not accurate enough. Therefore, the quantitative evaluation system of the negative externality of weathered crust elutiondeposited rare earth ore should be further explored.

\section{Data Availability}

The data used to support the findings of this study are included within the article.

\section{Conflicts of Interest}

The authors declare that they have no conflicts of interest.

\section{Acknowledgments}

The authors acknowledge funding for this work by the Science and Technology Research Project of Jiangxi 
Provincial Education Department (GJJ170506), the Project of Prosperity Philosophy and Social Science Research, Jiangxi University of Science and Technology (FZ18YB13), and the Jiangxi University of Technology Discipline Construction and Cultivation Project (JGXK-19-9).

\section{References}

[1] T. F. Li, Q. L. Xia, X. Q. Wang et al., "Metallogenic geological characteristics and mineral resource potential of rare earth element resources in China," Earth Sience Frontiers, vol. 25, no. 3, pp. 95-106, 2018.

[2] J. Y. Ding, "Historical review of the ionic rare earth mining:in honor of the 60 anniversary of GNMRI," Nonferrous Metals Science and Engineering, vol. 3, no. 4, pp. 14-19, 2012.

[3] R. A. Chi, J. Tian, X. P. Luo et al., "The basic research on the weathered crust elution-deposited rare earth ores," Nonferrous Metals Science and Engineering, vol. 3, no. 4, pp. 1-13, 2012.

[4] S. Q. Hu and J. P. Wu, "On the essence and classification of externality," Contemporary Finance \& Economics, vol. 10, pp. 5-14, 2011.

[5] S. Y. Zhang, "Carbon footprint compensation mechanism and practice of industrial enterprises from the perspective of externality theory," Journal of Chizhou University, vol. 30, no. 1, pp. 43-45, 2016.

[6] X. J. Zhou, "Application and evolution of externality theory in transportation," Railway Transport and Economy, vol. 30, no. 12 , pp. 12-18, 2008.

[7] G. P. Li and H. Y. Zhang, "The comparison between coal resources exploitation external costs and payable taxes," Economist, vol. 1, pp. 63-69, 2011.

[8] T. Bani-Mustafa, R. Flage, D. Vasseur et al., "An extended method for evaluating assumptions deviations in quantitative risk assessment and its application to external flooding risk assessment of a nuclear power plant," Reliability Engineering and System Safety, vol. 200, Article ID 106947, 2020.

[9] R. Costanza, R. D’Arge, R. de Groot et al., "The value of the world's ecosystem services and natural capital," Nature, vol. 387, no. 6630, pp. 253-260, 1997.

[10] Z. M. Xu, G. D. Cheng, and G. X. Wang, "A study on the estimation of economic loss from ecological deterioration-take Zhangye Prefecture as an example," Advance in Earth Sciences, vol. 14, no. 5, pp. 498-504, 1999.

[11] A. Papagiannis, D. Roussos, M. Menegaki, and D. Damigos, "Externalities from lignite mining-related dust emissions," Energy Policy, vol. 74, pp. 414-424, 2014.

[12] Z. M. Xu, X. W. Li, X. Y. Zhao et al., A Research on the Mechanism of Ecological Compensation in Typical Areas of Gansu Province, China Financial and Economic Publishing House, Beijing, China, 2011.

[13] G. P. Li and H. W. Li, "The perfection of user cost approach and the estimation of user cost of oil and gas resources of America," Journal of Natural Resources, vol. 28, no. 6, pp. 1046-1058, 2013.

[14] Z. Q. Zhang, Z. M. Xu, and G. D. Cheng, "The updated development and application of contingent valuation method (CVM)," Advances in Earth Science, vol. 18, no. 3, pp. 454463, 2003.

[15] Y. X. Ge, L. J. Liang, B. B. Wang et al., "Analysis on residents'willingness and payment of ecological compensation in Yellow River basin," China Rural Economy, vol. 10, pp. 77-85, 2009.
[16] The First National Pollution Source Census Leading Group Office, First National General Survey of Pollution Sources (The first volume), 2010.

[17] Z. Q. Guo, K. Zhao, J. F. Jin et al., "Problems facing ion adsorption type rare earth exploitation and research progresses on green extraction," Chemical Industry and Engineering Progress, vol. 38, no. 7, pp. 3425-3433, 2019.

[18] Y. M. Hu and H. P. Liu, "The latest research on radioactive pollution and radioactive detection in rare earth production," Rare Metals and Cemented Carbides, vol. 42, no. 2, pp. 32-35, 2014.

[19] Z. Y. Feng, X. W. Huang, M. Wang, and G. C. Zhang, "Progress and trend of green chemistry in extraction and separation of typical rare earth resources," Chinese Journal of Rare Metals, vol. 41, no. 5, pp. 604-612, 2017.

[20] S. Q. Liu, X. P. Wu, and H. E. Zhang, "Heat recovery of coke oven flue gas waste," Jiangxi Metallurgy, vol. 33, no. 6, pp. 15-16, 2013.

[21] L. G. Xu, "Construction scheme, function and elements of the rare earth industry reverse logistics network," Nonferrous Metals Science and Engineering, vol. 6, no. 4, pp. 121-124, 2015.

[22] L. G. Xu, Y. X. Wang, and S. T. Xu, "Enlightenment and international case reference of landscape restoration in nonferrous mines," Nonferrous Metals Science and Engineering, vol. 9, no. 4, pp. 89-96, 2018.

[23] C. G. Luo, X. P. Luo, N. N. Zhou et al., "Status and causes of ecological imbalance of abandoned rare earth mine in South China," China Mining Magazine, vol. 23, no. 10, pp. 65-70, 2014.

[24] L. G. Xu, Y. X. Wang, and J. W. Guan, "Negative externality feedback mechanism of rare earth resource development from the perspective of industrial chain security," Gold Science and Technology, vol. 27, no. 4, pp. 609-620, 2019.

[25] Z. Y. Chen and X. D. Zhu, "Accumulation of rare earth elements in bone and its toxicity and potential hazard to health," Journal of Ecology \& Rural Environment, vol. 24, no. 1, pp. 88-91, 2008.

[26] S. L. Hu, Y. Huang, G. S. Wang et al., "Adsorbing characteristics for Xinfeng weathered crust elution-deposited rare earth ores in southern Jiangxi Province," Journal of the Chinese Society of Rare Earths, vol. 35, no. 6, pp. 807-814, 2017.

[27] J. P. Wei, H. N. Wang, and J. B. Yan, "Environmental damages and control measures in exploiting ion-absorbed rare earth of South China," Nonferrous Metals Science and Engineering, vol. 7, no. 1, pp. 125-132, 2016.

[28] G. X. Ma, W. Q. Zhu, X. J. Wang et al., "The environmental cost assess-ment of China's rare earth resources development in 2001-2013," Journal of Natural Resources, vol. 32, no. 7, pp. 1087-1099, 2017.

[29] D. Lai and H. Q. Wang, "Benefit comparison between the full and incomplete costs of rare earth enterprise-take ion-type rare earth enterprise in Southern of China as an example," China Mining Magazine, vol. 23, no. 1, pp. 50-99, 2014.

[30] L. Qiu, Research on the Eco-Compensation Standards of Rare Earth Resources Exploitation in Ganzhou, Jiangxi University of Finance and Economics, Nanchang, China, 2013.

[31] L. G. Xu, "Analysis and comprehensive evaluation of the competitiveness of the rare earth industry in Jiangxi from the perspective of products and dialectics," Journal of Jiangxi University of Science and Technology, vol. 36, no. 6, pp. 36-40, 2015. 